\title{
AVALANCHE FORECASTING IN A HEAVY SNOWFALL AREA USING THE SNOWPACK MODEL
}

\author{
Hiroyuki Hirashima*, Kouichi Nishimura** ${ }^{* *}$ Satoru Yamaguchi ${ }^{*}$, Atsushi Sato* and Michael Lehning ${ }^{* \star \star}$
}

* Snow and Ice Research Center, NIED, Suyoshi, Maeyama, Nagaoka 940-0821, Japan

** Faculty of Science, Niigata University, Ikarashi, Niigata 950-2181, Japan

*** WSL, Swiss Federal Institute for Snow and Avalanche Research, SLF, Fluelastrasse 11, CH-7260 Davos Dorf, Switzerland

ABSTRACT: We describe the use of a snow cover model - SNOWPACK - for a heavy snowfall area. The area along the Sea of Japan received record-breaking snowfall in the winter of 2005/2006. Avalanche forecasting was carried out at Tunan, Niigata prefecture where snow exceeded $4 \mathrm{~m}$. Automated Meteorological Data Acquisition System operated by the Japan Meteorological Agency (AMEDAS) was used as the model input data. To verify the model output, snow pit observations were carried out in 10-day intervals. The snow profiles simulated using the SNOWPACK model agreed fairly well with the observed profiles. However, the equations for the stability index (SI) were not suitable for the study area considered. The empirical equations formulated by Yamanoi and Endo (2002) were most suitable for this region for simulating SI; therefore, they were incorporated into the SNOWPACK model. To expand the forecasting area to include the area around route 405 , a national road, the distributions of meteorological parameters in the study area were estimated for grid points with 10-m spacing.

One of the avalanches caused a disaster in which a car was pushed away from the road into a valley on $24^{\text {th }}$ December. The snow depth increased by about $70 \mathrm{~cm}$ within 24 hours; this caused a large load before densification. Thus, snow stability decreased. This was reproduced by the SNOWPACK model. Further, the stability index maps showed that most of slopes were dangerous on that day.

KEYWORDS: SNOWPACK model, avalanche forecasting, heavy snow, stability index

\section{INTRODUCTION}

In the winter of $2005 / 2006$, the region along the Sea of Japan received record-breaking snowfall. Hundred and fifty one people perished due to snow disasters such as accidents during the removal of snow, snow falling from the roof of houses, and avalanches. The Japan Meteorological Agency termed this winter of heave snowfall as 'Heisei 18-nen Gousetsu'. The areas most affected due to this heavy snowfall are located in Tunan, Niigata prefecture, Japan. The depth of the snow in this region was greater than 4 $\mathrm{m}$. Route 405 , a national road that passes the mountainous regions between the Niigataprefecture and the Nagano- prefecture, was exposed to an avalanche risk and was therefore closed. Further, the people living in these mountainous areas were isolated. In such situations, the estimation of the probability of an avalanche event would have been useful to decide whether the road should have been opened. Some professionals conducted a field survey and reported their findings to a road administrator. In addition to this, computational forecasting is a useful tool because it can simulate the snow conditions and the snow stability index that changes hourly. A computational model - SNOWPACKfor avalanche forecasting was developed in Switzerland (Lehning et al. (2002a), Lehning et al. (2002b), Bartelt et al. (2002)). It can also simulate the stability index (Lehning et al, 2004a) and forecast avalanches by combining a 3D model of surface process in a steep terrain (ALPINE3D, Lehning et al(2004b)). 
The SNOWPACK model was introduced in Japan. It was applied to the Honshu- area (Yamaguchi et al., 2004) and the Hokkaido- area (Hirashima et al., 2004a); and was thereby modified for application for Japanese winters. SNOWPACK simulations for a complex terrain were carried out by Nishimura et al. (2005) by combining the SNOWPACK model and the snow redistribution model (Liston and Sturm (1998), Hirashima et al. (2004b)). The validation of the avalanche forecasting by Nishimura et al. (2005) focused on the example of a slab avalanche. In this study, the avalanche forecasting model was applied around route 405 , which is wet and is a heavy snow area. This paper discusses suitable parameterization for estimating the stability index, predictable avalanche types, and future issues for an accurate avalanche forecasting.

\section{STUDY SITE}

The study site-Tunan $\left(36^{\circ} 59.8^{\prime} \mathrm{N}\right.$, $\left.138^{\circ} 41^{\prime} \mathrm{E}\right)$, Niigata prefacture, Japan - is an area of heavy snowfall. Figure 1 shows location and maps of the study area. The maximum snow depth this year was $416 \mathrm{~cm}$, whereas it is $215 \mathrm{~cm}$ for an average year. Since this area lies in a temperate region in a snowy area, faceted crystals and depth hoar are rarely formed. Avalanches tend to occur during heavy snowfall and on warm days.

The Automated Meteorological Data Acquisition System operated by the Japan Meteorological Agency (AMEDAS) observes air temperature, wind speed, wind direction, precipitation, duration of sunshine, and snow depth. The AMEDAS data was used as model input data.

Since the AMEDAS does not observe solar radiation and longwave radiation, the empirical equations suggested by Kondo et al. (1991) were used in order to estimate them. The input solar radiation $S^{\downarrow}\left(\mathrm{Wm}^{-2}\right)$ was calculated as follows by using the incident solar radiation at the top of the atmosphere $S_{0}{ }^{\downarrow}\left(\mathrm{Wm}^{-2}\right)$ and the duration of sunshine.

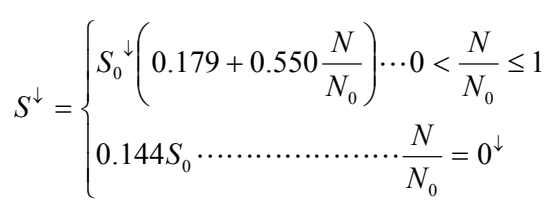

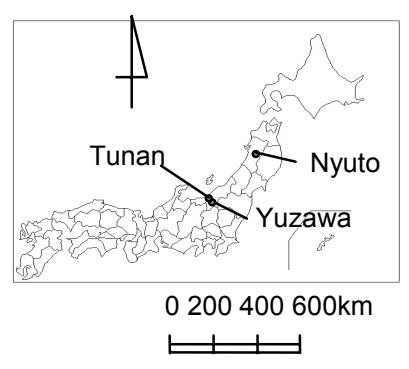

a

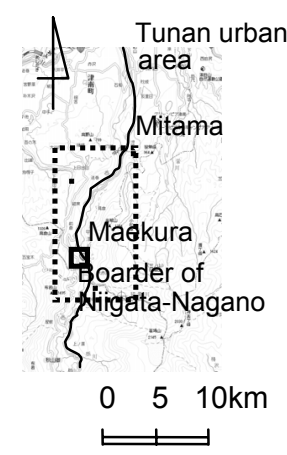

b
Figure 1: Study area (a:Locations of Tunan, Yuzawa, and Nyuto, b:Map of Tunan). The dotted rectangle shows the area simulated. The solid rectangle shows the area of Fig. 6 .

$S_{0}{ }^{\downarrow}=I_{00}\left(\frac{d_{0}}{d}\right)^{2} \cos \theta$

Where, $\mathrm{N}$ is the duration of sunshine; $\mathrm{N}_{0}$, the possible duration of sunshine; $\mathrm{I}_{00}$, the solar constant $\left(=1365 \mathrm{Wm}^{-2}\right) ; \mathrm{d}$, the distance between the earth and the sun; $d_{0}$, the average of distance between the earth and sun; and $\theta$, is the zenith angle.

Longwave radiation is also estimated from meteorological data as follows:

$$
\begin{aligned}
& L^{\downarrow}=\sigma T^{4}[1-(1-\chi) C]
\end{aligned}
$$

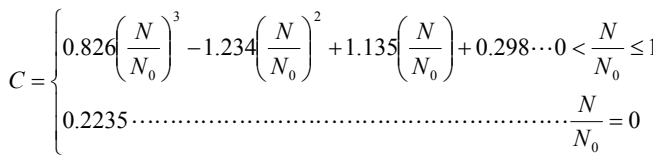

$$
\begin{aligned}
& \chi=0.74+0.19 x+0.07 x^{2}
\end{aligned}
$$

where $x$ is the logarithm of the column effective water vapour.

\section{OBSERVATIONS}

\subsection{Snow pit observations}

Snow pit observations were carried out from January to March at the AMEDAS point at 10- day intervals. The snow conditions observed are shown in Fig. 2. The snow profiles showed that the snow comprises new snow, decomposed 

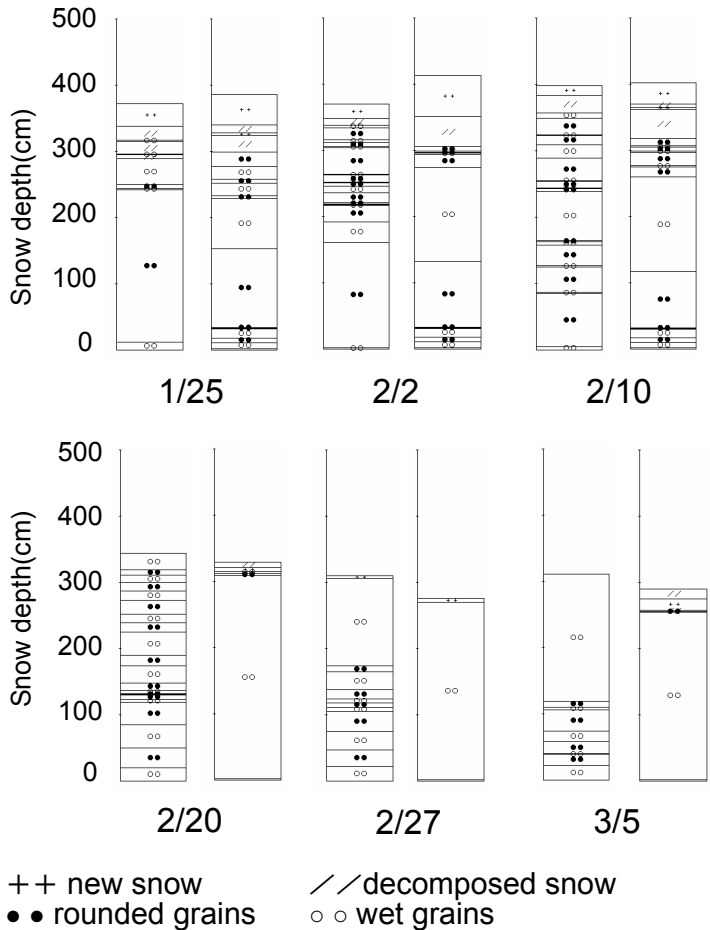

Figure 2: Snow cover structures for each observed day. The left profiles are the observed results, and those on the right are the simulated ones.

snow, rounded grains, and wet grains. However, no faceted grains and depth hoar were observed. The wet grains observed at the bottom layer were formed at the beginning of winter. The wet grains at the middle layer were formed on $14^{\text {th }}$ and $15^{\text {th }}$, January, which were warm days with rainfall. Most of the layers became wet grains after $20^{\text {th }}$

February.

\subsection{Remote sensing}

Remote sensing observations were carried out for topographic surveys and avalanche detections. First, the topographic surveys by laser measurements were carried out using an ALS50 Airborne Laser Scanner and aircraft on $25^{\text {th }}$ February, 2006 in order to evaluate the distribution of snow depth. This depth distribution can be obtained from the difference between the surface altitude of the ground surface in a snow season and in a non- snow season. Since the topographic data of the non- snow season were not obtained from the laser measurement, a 10-m mesh DEM, which was obtained from a 1:25000 map of the Geographical Survey Institute (GSI), was substituted for topographic data for the non- snow season. Since the error in topographic data was too large for estimating the snow depth by subtraction, the snow depth obtained was of poor quality. Therefore, the laser measurements in the non- snow season need to be carried out in order to correct the snow depth distribution. This is under consideration.

Second, aerial photographs were taken in order to develop the avalanche distribution map on $5^{\text {th }}$ March. Hundred and sixty four surface avalanches and five full- depth avalanches were detected in an area of $40.2 \mathrm{~km}^{2}$. Further, $5.9 \%$ areas were affected by avalanches. The slope angles of fracture line $(\alpha)$ and sighting angles from the extreme runout position to the top of the starting point $(\beta)$ were estimated for each avalanche. The frequency distributions of $\alpha$ and $\beta$ for surface avalanches are shown in Fig. 3 . The average value of $\alpha$ was $41.2^{\circ}$. Two-thirds of avalanches (about $69 \%$ ) occur for slopes with inclinations between $35^{\circ}$ to $45^{\circ}$ (Fig.3a). This result shows that avalanches frequently occur

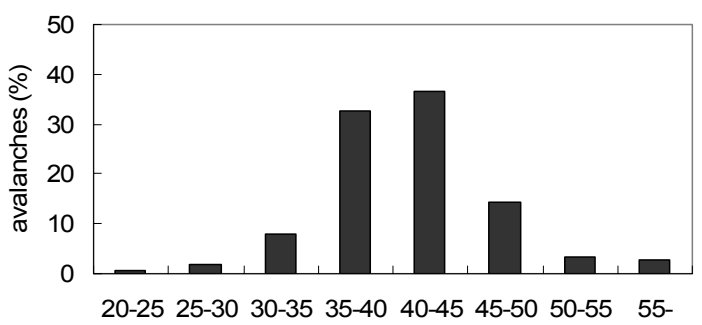

a

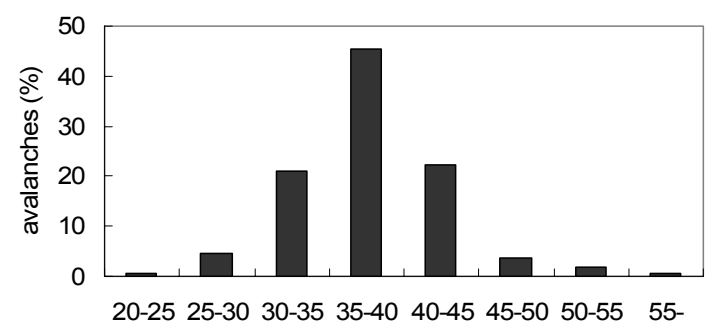

$\beta$

b

Figure 3: Frequency distribution of $\alpha$ and $\beta$ for a surface avalanche. 
more steep slopes than the result of fracture line study conducted by McClung and Schaerer (1993). The average value of $\beta$ was $37.9^{\circ}$. Further, $88.6 \%$ of $\beta$ of avalanches ranged $30-45^{\circ}$ (Fig. $3 b$ ).

\section{NUMERICAL SIMULATIONS}

\subsection{SNOWPACK result}

Simulated snow profiles are shown in Fig. 4. Snow accumulation begins in early December. The snow depth approached about $4 \mathrm{~m}$ in early January. Since snow metamorphosed under small temperature gradient conditions, faceted grains and depth hoar were rarely formed. On $14^{\text {th }}$ and $15^{\text {th }}$ January, the upper layer snow metamorphosed to wet grains since they were warm days with rainfall. All the snow layers were transformed into wet grains on $15^{\text {th }}$ February. The comparisons between the observed snow types are shown in Fig. 2. The simulated snow profiles agreed fairly well with the observed result. However, the simulated results appeared to overestimate a snowmelt. One of the causes of this discrepancy is the shortwave and longwave radiation that was estimated using an empirical equation.

\subsection{Estimation of snow stability index}

Snow stability index (SI) is the shear strength divided by the shear stress. The calculated profiles of SI are shown in Fig.4b. The SI of compacted snow layer was about 1.0 from early January to middle February. Thus, the compacted snow appeared to be weak layer, and this dangerous situation lasted longer than a month. However, in fact, compacted snow is stable against an avalanche. The original SNOWPACK model estimates shear strength using the empirical equation suggested by Jamieson and Johnston (2001) who formulated the relationship between the shear strength and the snow density for each snow type. This relationship was derived for relatively light snow (less than $270 \mathrm{~kg} / \mathrm{m}^{3}$ ). However, in a heavy snow area, the snow density at the lower layer exceeds $400 \mathrm{~kg} / \mathrm{m}^{3}$ even if the snow is dry. Thus, the equations of Jamieson and Johnston (2001) are not suitable for estimating shear strength in such a heavy snow area. This formula underestimated the
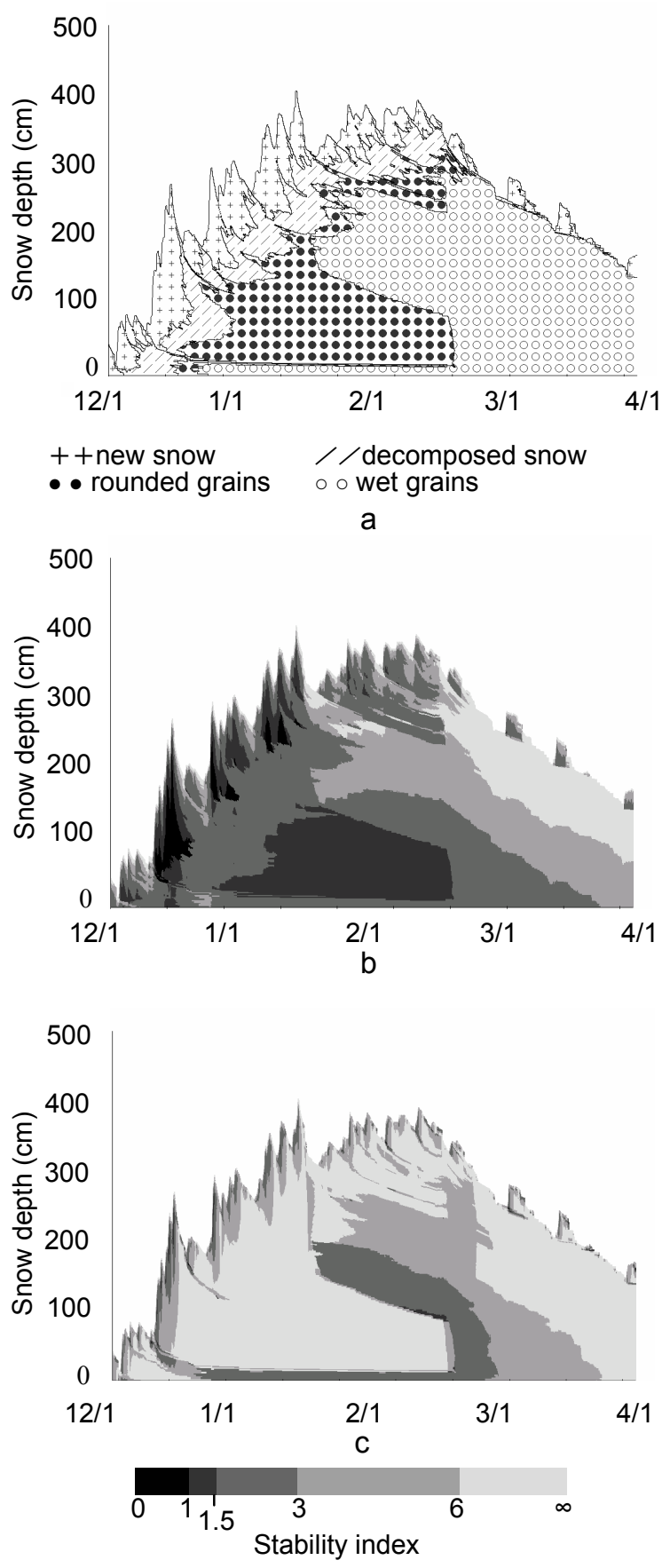

Figure 4: Simulated snow profile at the Tunan AMEDAS point. a: snow type, b: SI calculated using the original SNOWPACK, c: SI calculated using the equation of Yamanoi and Endo(2002) and Abe et al. (2005). 
shear strength of heavy snow. Further, rounded grains at the lower layer were considered as unstable although compacted snow at the lower layer is in fact stable. Therefore, an alternate formula is needed for measuring shear strength for heavy snow. The relationships between snow density and shear strength have also been studied in Japan. Yamanoi and Endo (2002) formulated the shear strength $\sigma\left(\mathrm{Nm}^{-2}\right)$ as:

$$
\sigma=K \rho_{d r y}{ }^{2.91} e^{-0.235 \theta}
$$

where $\rho_{\text {dry }}$ is the dry density; $\theta$, the volumetric water content; and $\mathrm{K}$, a constant that is determined experimentally by the snow type. $\mathrm{K}$ is $9.40 \times 10^{-4}$ for new snow, decomposed snow and rounded grains, and $4.97 \times 10^{-4}$ on wet grains. This formulation was derived from snow where densities range from $50 \mathrm{kgm}^{-3}$ to $500 \mathrm{kgm}^{-3}$. The shear strength of faceted grains and depth hoar is formulated by Abe et al. (2005) as follows:

$$
\sigma=K \exp \left(1.41 \times 10^{-2} \rho_{d r y}\right)
$$

where $\mathrm{K}$ is $3.91 \times 10^{-2}$. This formulation was derived from snow densities ranging from $150 \mathrm{kgm}^{-3}$ to 350 $\mathrm{kgm}^{-3}$. Yamanoi et al. (2004) formulated a shear strength depending on the hardness measured by a digital push gauge. This equation is expressed as:

$$
\sigma=0.0180 H^{1.18}
$$

where $\mathrm{H}$ is hardness $\left(\mathrm{Nm}^{-2}\right)$. The hardness profiles were measured on $27^{\text {th }}$ February. On that day, all the snow layers were wet, and unfortunately no hardness data for dry snow could be measured in the snow pit observations at Tunan. However, the hardness profiles for dry snow were observed at Yuzawa, which is located about $13 \mathrm{~km}$ southeast of Tunan on $4^{\text {th }}$ January. The shear strength profiles were estimated using these hardness profiles and Eq. (7). Further, shear strengths were calculated from snow types and snow densities by using the equations by Yamanoi and Endo (2002) (Eq. (5)), Jamieson and Johnston (2001), and Perla (1982). The comparisons betweenn these estimations are shown in Fig. 5. The mean bias error (MBE), the root mean square error (RMSE) and the correlation coefficient $\left(r^{2}\right)$ for each equation compared with the value estimated from hardness are shown in Table. 1. Obviously, the shear strengths estimated by Yamanoi and Endo (2002) exhibited the smallest error for the dry snow condition. Thus, their estimation is most suitable for this region. On the other hand, the errors for wet snow were comparable with the equation of Perla (1982). Equations (5) and (6) were incorporated into SNOWPACK. The simulated result using new parameterization was shown in Fig. 4c. The SI decreased during heavy snowfall, and wet grains sometimes served as a weak layer.
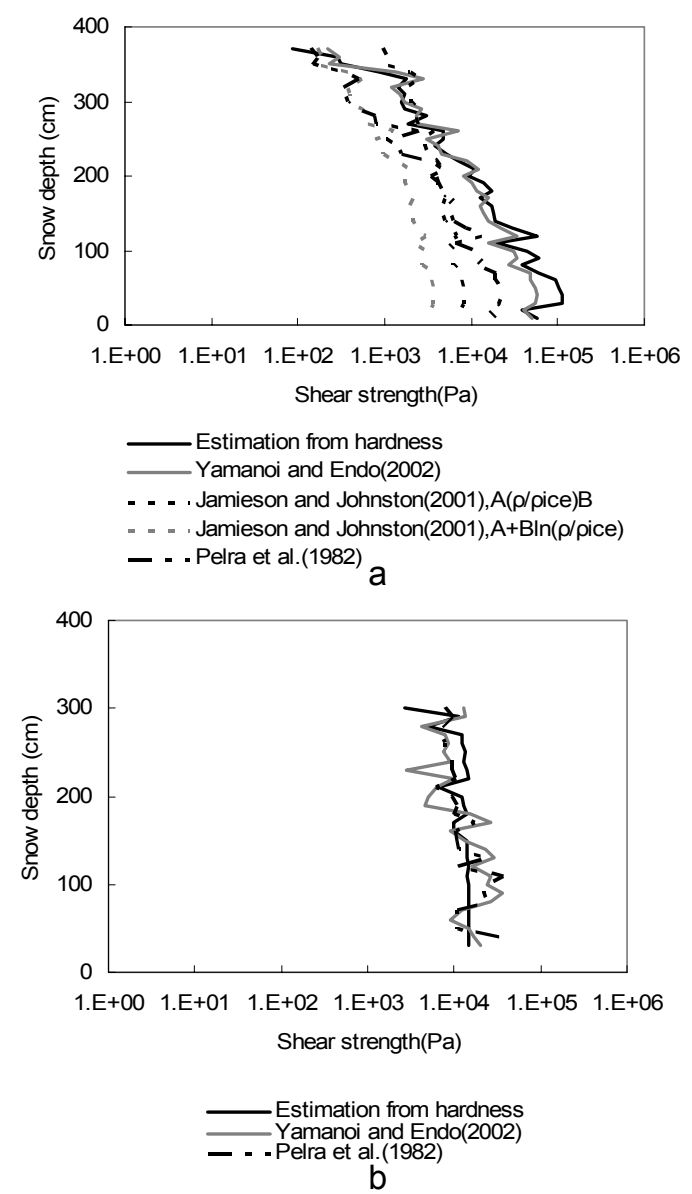

Figure 5: Comparisons of each estimation technique for SI. Estimated value from hardness is used as true value. a: profiles of shear strength at Yuzawa where snow was dry. b: profiles at Tunan where snow was wet. 
Table 1: MBE, RMSE, and $r^{2}$ for each calculated results compared with estimated value from hardness. In the column of Jamieson and Johnston (2001), (1) is the result using the equation formulated by linear regression of In $\sigma=A+B\left(\rho / \rho_{\text {ice }}\right)$ and $(2)$ is the result of $\sigma=A\left(\rho / \rho_{\text {ice }}\right)^{B}$.

\begin{tabular}{lrrrrr}
\hline \multicolumn{5}{c}{ Jamieson } & \multicolumn{3}{c}{ Jamieson } \\
& $\begin{array}{c}\text { Yamanoi and and Johnston and Johnston Perla et al. } \\
\text { Endo (2002) }\end{array}$ & $(2001)(1)$ & $(2001)(2)$ & $(1982)$ & \\
\hline MBE & -0.06 & -0.37 & -0.85 & -0.50 \\
RMSE & 0.17 & 0.64 & 0.94 & 0.53 \\
$\mathrm{r}^{2}$ & 0.97 & 0.94 & 0.96 & 0.96 \\
\hline
\end{tabular}

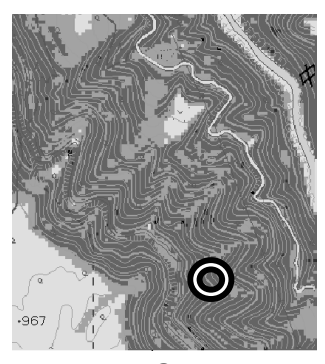

a

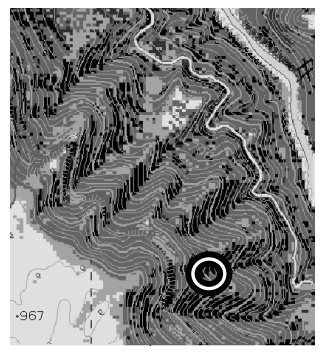

C

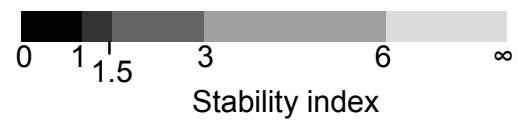

Figure 6: Simulated SI maps. a: $23^{\text {rd }}, \mathrm{b}: 24^{\text {th }}$, and c: $25^{\text {th }}$ in December. White circles on black background indicate the position of the avalanche point.

\subsection{Simulations for the area of route 405}

SI distribution maps were charted using a 10-m mesh around route 405. GISMAP Terrain a 10-m mesh DEM obtained from 1:25,000 maps of GSI was used as topographic data. Local variation of meteorological conditions such as air temperature, solar radiation, and wind speed were calculated using techniques similar to those of Nishimura et al. (2005).

As an example, the SI maps between $23^{\text {rd }}$ and $25^{\text {th }}$ December are shown in Fig. 6 . The SI maps show that most of the steep slopes were subject to avalanche danger on $24^{\text {th }}$ December despite being relatively safe on the previous and next days. In fact, on that day, the avalanche that occurred pushed a car away from the road into the valley. Thus, this region was avalanche prone. The profiles for snow type and SI around the day of the avalanche are shown in Fig. 7. The SNOWPACK result shows that SI decreases in a new snow layer. The snow depth increased by about $70 \mathrm{~cm}$ within 24 hours. This leads to an unstable snow condition since the snow was strongly loaded with newer snow before
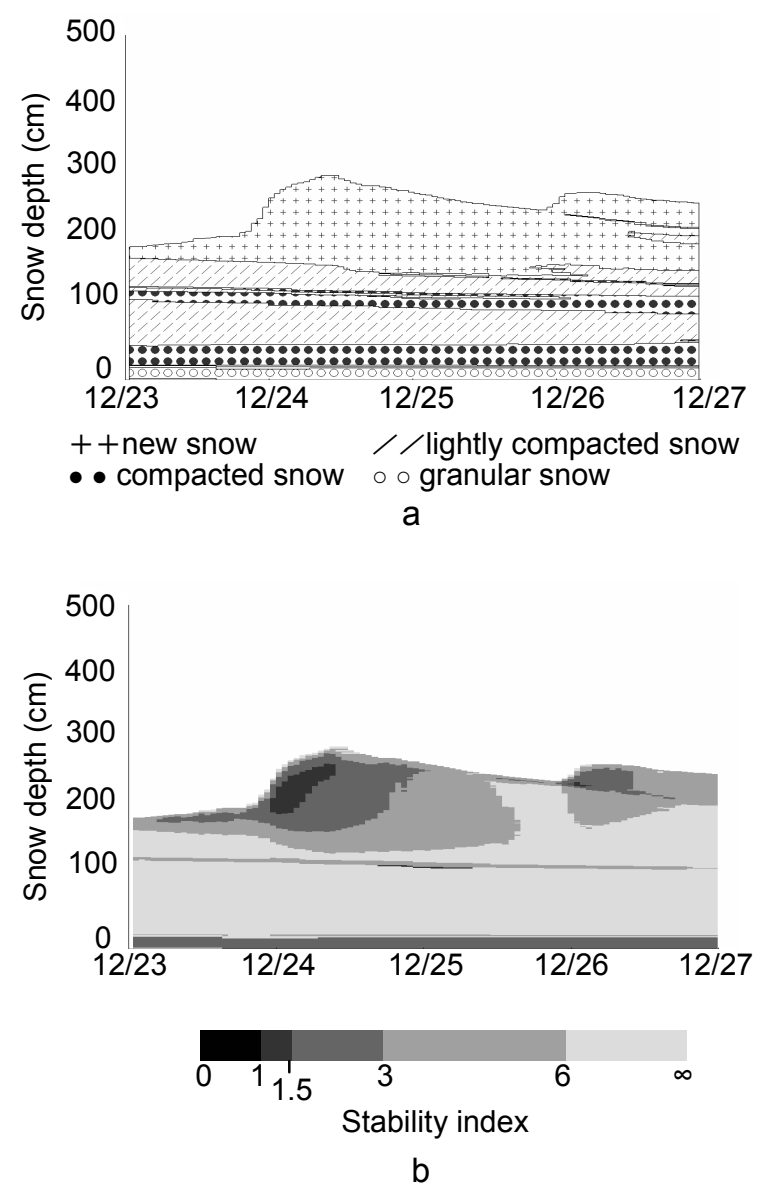

Figure 7: SNOWPACK result around the day of avalanche. a: snow structure, b: SI 
densification. The weak layer was not detected in the snow pit observation of $25^{\text {th }}$ December. However, the depth of the new snow layer exceeded $40 \mathrm{~cm}$. The simulated result reproduced this condition well.

\section{DISCUSSION}

\subsection{Predictability of an avalanche accident}

SNOWPACK simulation needs meteorological input. However, avalanche accidents do not

occur in locations that are complete with meteorological instruments. Thus, meteorological data of some distance (about $10 \mathrm{~km}$ on an average) have to be used. Moreover, the use of an estimate equation for non-observed parameters (solar and long wave radiation in this study case) leads to an increase in simulation errors. Nevertheless, the avalanche due to heavy snowfall around route 405 could have been predicted by using this method.

Several large avalanche accidents occurred in other regions in this year. SNOWPACK simulations were carried out when these avalanche accidents occurred. In this paper, two examples of comparisons between the SNOWPACK simulations and the avalanche accidents are discussed. One is the avalanche that occurred at Yuzawa, Niigata- prefecture, and the other is the one that occurred at Nyuto-Onsen, Akita- prefecture.

\section{(a) avalanche at Yuzawa}

Figure 1 also shows the location of Yuzawa where some avalanche accidents occurred. Large scale avalanche with debris size $1.8 \times 10^{4} \mathrm{~m}^{3}$ occurred on $28^{\text {th }}$ December at Tuchital (about $10 \mathrm{~km}$ south-southeast from the Yuzawa urban area). The vertical drop between the avalanche generation point and the debris deposited area was more than $600 \mathrm{~m}$. The avalanche hit and uprooted an electric pole and snapped the wires. Furthermore, several avalanches occurred on $3^{\text {rd }}$ and $4^{\text {th }}$ January at three ski areas and national road route 17 , which connects Tokyo and Niigata. The SNOWPACK simulation was carried out by using the AMEDAS meteorological data of Yuzawa and the snow depth data of Tuchital (station nearest to the avalanche point) as the model input data. When the avalanche accident occurred at Tutital (on $28^{\text {th }}$ December), the SI declined to 1.4 in the new snow layer. Heavy snowfall and collapse of new snow layer appear to be the causes of the avalanche, similar to the avalanche discussed in section 4.3. While several avalanches occurred (from $3^{\text {rd }}$ and $4^{\text {th }}$ January), the SI ranged $1.6-2.2$ in the new snow layer. Rounding facets, which is an intermediate condition between decomposed snow and faceted grains, were detected. Such a layer was also detected in a snow pit observation carried out on January $4^{\text {th }}$. Although the observed SI was 1.08 at the rounding facets layer, the simulated SI was 3.0. The calculated shear strength of the rounding facets was similar to that of decomposed snow. If shear strength was calculated as faceted grains, it would have been 0.7 . This result suggests that the estimation of shear strength for intermediate condition is important for the avalanche prediction generated by the failure of the intermediate snow types.

\section{(b) avalanche at Nyuto Onsen}

Most large avalanche accidents in this winter occurred on $10^{\text {th }}$ February at Nyuto-onsen, which is a hot spring resort in the Akita- prefecture. The avalanche occurred at three points on the northwest facing slope, resulting in the death of one and the injury of 16 people. The air temperature and the snow depth observed near the avalanche point was used as model input data. The other meteorological parameters were obtained from AMEDAS at Tazawako, which is located about $12.6 \mathrm{~km}$ southwest from the avalanche point. The SNOWPACK simulation showed that the SI declined to 1.7 in a new snow layer when an avalanche accident occurred. A relatively weak layer was detected $100 \mathrm{~cm}$ under the surface. This layer was also detected by a snow pit observation carried out on $11^{\text {th }}$ February. Both the observed SI and the simulated SI were 2.9; these values were too large to generate an avalanche. Thus, this avalanche appears to be generated by the collapse of the new snow.

\subsection{Future issues}


Destabilization during heavy snowfall was predicted by the SNOWPACK model. However, some issues exist.

First, SI declines remarkably in most of steep slopes during heavy snowfall (Fig. 6b). The specification of a dangerous location of an avalanche is difficult at present. One of the useful methods to specify dangerous place is the prediction of a snow cornice. The snow cornice can be predicted by simulating a snow redistribution. It has to be validated by using the observed snow depth distribution. Since topographic surveys using laser measurements in a snowy season have already been carried out, snow depth distribution can be obtained by laser measurement during the non- snow season mentioned in section 3.2. Then, the accuracy enhancement for avalanche prediction will be favourable.

Second, surface avalanches due to the failure of wet grains and full depth avalanches as well as the avalanches caused by collapse of new snow often occur in temperate snowy area. The shear strength of wet grains declines exponentially with volumetric water content (Yamanoi and Endo, 2002). Full depth avalanches tend to occur when liquid water (snowmelt water or rain) arrives at the boundary of the ground. Accurate simulation for moisture movement in the snowpack is necessary for the prediction of these avalanches. The moisture movement scheme in the SNOWPACK model is that the liquid water moves downwards when exceeds a certain value. However, the above two avalanche types are affected by more complex water movement. Thus, we plan to develop a numerical snowpack model considering existence regime of liquid water (capillary regime, pendular regime, and funicular regime (Colbeck, 1973)), the formation of water pass, and the water movement through the water pass (Colbeck, 1978).

\section{CONCLUSIONS}

Application of the snow cover model SNOWPACK - to avalanche forecasting for a heavy snow area was carried out. Snow pit observations were also carried out in 10- day intervals. During this winter, snow depth exceeded $4 \mathrm{~m}$ in the study region, Tunan. The pit observations revealed that the snowpack comprises new snow, decomposed snow, rounded grains, and wet grains without faceted grains and depth hoar. The profiles simulated by the SNOWPACK model agreed with the observed profiles fairly well. However, the equations for stability index (SI) were not suitable for this study area. The empirical equations formulated by Yamanoi and Endo (2002) and Abe et al. (2005) were incorporated to calculate SI. Then, the calculated SI agreed better with the SI estimated from the hardness.

In order to expand the forecasting area to include route 405 , a national road, we used data from an AMEDAS and a DEM with a grid size of $10 \mathrm{~m}$. The distribution of meteorological parameters were estimated and used for the SNOWPACK simulation in order to obtain the distribution of SI. The SI maps showed considerable decline during the heavy snowfall; however, they stabilized after the snow stopped. Avalanche accidents occurred when the SI maps depicted an unstable condition. Further, it was shown that this model can be used for avalanche prediction. However, a number of improvements are necessary. The specification of a dangerous avalanche location is still difficult since the characteristic of snow depth distribution is unclear. However, it is expected to be clarified by laser measurement. Modelling liquid water movement is also an important issue for a temperate and heavy snow region like this study region. We are planning to develop a Japanese snowpack model that focuses on liquid water movement in the snowpack.

\section{ACKNOWLEDGEMENT}

This study was supported by Special Coordination Fund for the Promotion of Science and Technology, and grant from the Ministry of Education, Science, Sports and Culture, Japan (No. 17800006: principal investigator A. Sato). We specially thank T. Sato and M. Nemoto of the NIED, and K. Izumi and K. Kawashima of the Niigata University for their assistance with the snow pit observations. We are also grateful to Highland Agricultural Technology Center for providing us with a place for carring out the observations.

\section{REFERENCES}


Abe, O., S. Mochizuki., S. Yamaguchi, H. Hirashima, and A. Sato. 2005: Shear strength of depth hoar snow layers. Proceedings of cold region technology conference. 21, 249-252. (in Japanese)

Bartelt, P. and M. Lehning. 2002. A physical SNOWPACK model for the Swiss avalanche warning. Part I. numerical model. Cold Reg. Sci. Technol. 35(3), 123-145.

Colbeck, S. C. 1973: Theory of metamorphism of wet snow. CREEL Res. Rep., 313

Colbeck, S. C. 1978: The physical aspects of water flow through snow. Adv. Hydrosci., 11, 165-206.

Jamieson, J. B. and C. D. Johnson, 2001: Evaluation of the shear frame test for weak snowpack layers. Ann. Glaciol., 32, 59-68.

Hirashima, H., K. Nishimura, E. Baba, A. Hachikubo, and M. Lehning 2004a: SNOWPACK model simulations for snow in Hokkaido, Japan.

Ann. Glaciol. 38, 123-129.

Hirashima, H., T. Ohata, Y. Kodama, H. Yabuki, N. Sato, and A. Georgiadi, 2004b: Non-uniform distribution of tundra snow cover in eastern Siberia, J. Hydromet. 5(3), 373-389.

Kondo, J., T. Nakamura and T. Yamazaki, 1991: Estimation of the solar and downward atmospheric radiation. Tenki, 38, 41-48 (in Japanese).

Lehning, M., P. Bartelt, B. Brown, C. Fierz and P. Satyawali. 2002a. A physical SNOWPACK model for the Swiss avalanche warning. Part II. Snow microstructure. Cold Reg. Sci. Technol. 35(3), 147-167.

Lehning, M., P. Bartelt, B. Brown and C. Fierz 2002b. A physical SNOWPACK model for the Swiss avalanche warning. Part III. meteorological forcing, thin layer formation and evaluation. Cold Reg, Sci. Technol. 35(3), 169-184.

Lehning, M., C. Fierz., B. Brown, and B. Jamieson, 2004a: Instability for snow cover model SNOWPACK. Ann. Glaciol. 38, 331-338.

Lehning, M., P. Bartelt, S. Bethke, C. Fierz., D. Gustafsson, B. Landl, and M. Lütschg, O. Martius, I. Meirold, N. Raderschall, J. Rhyner, and M. Stähli, 2004b: Review of SNOWPACK and ALPINE3D applications. Proceedings of the $5^{\text {th }}$ International Snow Engineering Conference, Davos, Swizerland, Bartelt, Adams, Cheisten, Sack\&Sato (eds), Balkema: 299—307.
Liston, G. E., and M. Sturm, 1998: A snowtransport model for complex terrain. J. Glaciol., 44, 498-516.

McClung, D. and P. Schaerer, 1993: The Avalanche Handbook, The Mountaineers, Seattle, $271 \mathrm{pp}$.

Nishimura, K., E. Baba., H. Hirashima, and M. Lehning, 2005: Application of the snow cover model SNOWPACK to snow avalanche warning in Niseko, Japan. Cold Reg. Sci. Technol. 43, 62-70.

Yamaguchi, S., A. Sato and M. Lehning. 2004:

Application of the numerical snowpack model (SNOWPACK) to the wet snow region in Japan. Ann. Glaciol., 38, 266-272.

Yamanoi, K. and Y. Endo. 2002: Dependence of shear strength of snow cover on density and water content. Seppyo., 64(4), 443-451. (in Japanese with English abstract)

Yamanoi, K., Y. Takeuchi, and S. Murakami. 2004: Evaluation of snow stability index by using a digital push-gauge. Seppyo., 66(6), 669-676. 